\title{
A glycinergic projection from the ventromedial lower brainstem to spinal motoneurons. An ultrastructural double labeling study in rat
}

\author{
J.C. Holstege and C.M.H. Bongers \\ Department of Anatomy, Erasmus University Medical School, Rotterdam (The Netherlands)
}

(Accepted 27 August 1991)

Key words: Glycine; Motoneuron; Spinal cord; Brainstem; Sleep; Electron microscopy; Immunogold; Locomotion

\begin{abstract}
In the present study it was determined whether glycine was present in the descending brainstem projections to spinal motoneurons in the rat. For this purpose injections of wheatgerm agglutinin-horseradish peroxidase (WGA-HRP) were made in the ventromedial part of the lower brainstem at the levels of the rostral inferior olive and the caudal facial nucleus. After perfusion, WGA-HRP histochemistry was performed, followed by the postembedding immunogold technique with an antibody against glycine. Electron microscopical examination of the lumbar motoneuronal cell groups showed that $15 \%$ of the WGA-HRP labeled terminals, derived from the ventromedial reticular formation, were also labeled for glycine. The majority $(91 \%)$ of these double labeled terminals were of the F-type (containing many flattened vesicles), while the remaining $9 \%$ were of the S-type (containing mostly spherical vesicles). Many of the double labeled terminals established a synapse, mostly with proximal and distal dendrites. The present data, combined with our previous findings that $40 \%$ of the projections from the same ventromedial brainstem area to lumbar motoneurons contained $\gamma$-aminobutyric acid (GABA), indicate that over 50\% of these brainstem projections contain GABA and/or glycine, exerting a direct inhibitory effect on spinal motoneurons. The possibility that the glycinergic fibers within these projections play an important role in producing muscle atonia during rapid eye movement (REM) sleep is discussed.
\end{abstract}

The projections from the lower brainstem to the spinal cord have been extensively investigated, both with retrograde and anterograde tracing techniques (for a review see ref. 14). It was demonstrated that the projection fibers from the ventromedial reticular formation and the adjacent raphe nuclei of the caudal brainstem terminated in all laminae, including the spinal motoneuronal cell groups, throughout the spinal cord. Ultrastructural studies on these projections ${ }^{10,13}$ showed that their terminals within the motoneuronal cell groups could be subdivided in morphologically different types: F-type terminals (containing many flattened vesicles), S-type terminals (containing many spherical vesicles) and G-type terminals (containing many dense cored (granular) vesicles). In addition it was found ${ }^{13}$, by combining the anterograde transport of $\left[{ }^{3} \mathrm{H}\right]$ leucine from the ventro-medial reticular formation with the retrograde transport of horseradish peroxidase (HRP) from the hindleg muscles, that over $50 \%$ of the radioactively labeled terminals derived from the lower brainstem actually contacted HRP labeled dendrites of motoneurons in the lumbar spinal cord.

Recently we have started to investigate whether the different types of terminals, which were labeled from the ventromedial brainstem, could be correlated with different transmitters. Dahlstrom and Fuxe ${ }^{6}$ showed that there exists a prominent serotonergic projection from the ventromedial brainstem to the spinal cord, including the motoneuronal cell groups. These findings were confirmed in studies ${ }^{2,28}$ combining retrograde tracing from the spinal cord with immunocytochemistry for serotonin. These studies also showed the existence of a prominent nonserotonergic spinal projection from the ventromedial brainstem, suggesting that, apart from serotonin, one or more other transmitters were present in those projections. In the motoneuronal cell groups, serotonin is contained within G-type terminals ${ }^{31}$ which originate mainly in the raphe nuclei of the lower brainstem and to a much lesser extent in the adjacent ventromedial reticular formation $^{13}$. The latter area gives rise mainly to (non-serotonergic) F-type terminals ${ }^{10,13}$. By using the combination of wheat-germ agglutinin coupled to HRP (WGA-HRP) anterograde tracing with the postembedding immunogold technique for $\gamma$-aminobutyric acid (GABA) ${ }^{7}$, we have recently established ${ }^{11}$ that GABA is present in many of the F-type terminals derived from the ventro-medial reticular formation at the level of the rostral inferior olive and the caudal facial nucleus. However, it was also found that Correspondence: J.C. Holstege, Dept. of Anatomy, Erasmus University Medical School, P.O. Box 1738, 3000 DR Rotterdam, The Neth-
erlands. 
some of the F-type terminals derived from the ventromedial reticular formation were not labeled for GABA, suggesting that they contained another transmitter. In the motoneuronal cell groups, F-type terminals were found to contain either $\mathrm{GABA}^{12,19,23}$ or glycine ${ }^{19,22,32}$. We have initiated the present study to determine whether glycine was present in the non-GABAergic F-type terminals derived from the ventromedial reticular formation. The findings presented in this paper show that in lumbar motoneuronal cell groups approximately $15 \%$ of the terminals labeled with WGA-HRP from the ventromedial reticular formation contained glycine.

Three rats were used for ultrastructural analysis. In short the following steps were taken (for details of the procedure see ref. 11). The rats were deeply anaesthetized with pentobarbital $(60 \mathrm{mg} / \mathrm{kg})$ and injected with $0.15 \mu \mathrm{l}$ WGA-HRP (5\% in saline) in the ventromedial part of the reticular formation at the level of the rostral inferior olive and the caudal part of the facial nucleus. After 3 days survival, the animals were re-anaesthetized with pentobarbital and perfused transcardially with $40 \mathrm{ml}$ saline in phosphate buffer (0.1 M, pH 7.3) immediately followed by 11 of $5 \%$ glutaraldehyde in phosphate buffer (0.1 M, pH 7.3). After perfusion, the brainstem and lumbar spinal cord were dissected. From the brainstem injection sites, frozen sections were cut, incubated with diaminobenzidine (DAB) 9 , counterstained with Cresyl violet and coverslipped. The 5th and 6th lumbar segments were cut in slabs $(75 \mu \mathrm{m})$ on a vibratome slicer. These slabs were then reacted for WGA-HRP using tetramethylbenzidine (TMB) as a chromogen ${ }^{24}$ and the re- action product was stabilized with DAB-Cobalt ${ }^{18}$. The slabs were postfixed with osmium tetroxide $(1.5 \%$ in phosphate buffer (pH 7.3) containing 8\% glucose), chemically dehydrated ${ }^{26}$ and flat-embedded in Araldite. The plastic embedded vibratome sections were examined in the light microscope and from each rat the two sections with the highest amount of WGA-HRP labeling were selected. They were glued to plastic blocks and pyramids were made, containing the entire lateral motoneuronal cell group. Ultrathin sections were cut and collected on formvar coated nickel one hole grids. These were incubated overnight at $4{ }^{\circ} \mathrm{C}$ with a polyclonal glycine antibody (kindly provided by $\mathrm{Dr}$. R.J. Wenthold, for specificity tests, see ref. 33), diluted 1:250 in Tris buffered saline ( $0.05 \mathrm{M}, \mathrm{pH} 7.6)$, containing $0.1 \%$ Triton $\mathrm{X}-100$, followed by a $2 \mathrm{~h}$ incubation with a goat anti-rabbit antibody, labeled with $15 \mathrm{~nm}$ gold particles (Amersham). The sections were counterstained with lead citrate and uranyl acetate and examined in a Philips 300 electron microscope. From each rat two blocks were used for analysis and from each block two sections (at least $1 \mu \mathrm{m}$ apart) were analyzed, i.e. a total of 12 sections. The data obtained in the various sections were grouped together and the results were expressed as percentages.

The light microscopic sections of the lower brainstem showed that the WGA-HRP injection site was located in the ventromedial reticular formation at the level of the rostral inferior olive and the caudal part of the facial nucleus (Fig. 1). This area included the gigantocellular reticular nucleus pars ventralis and pars $a$ and part of the paragigantocellular reticular nucleus ${ }^{1}$. The injection

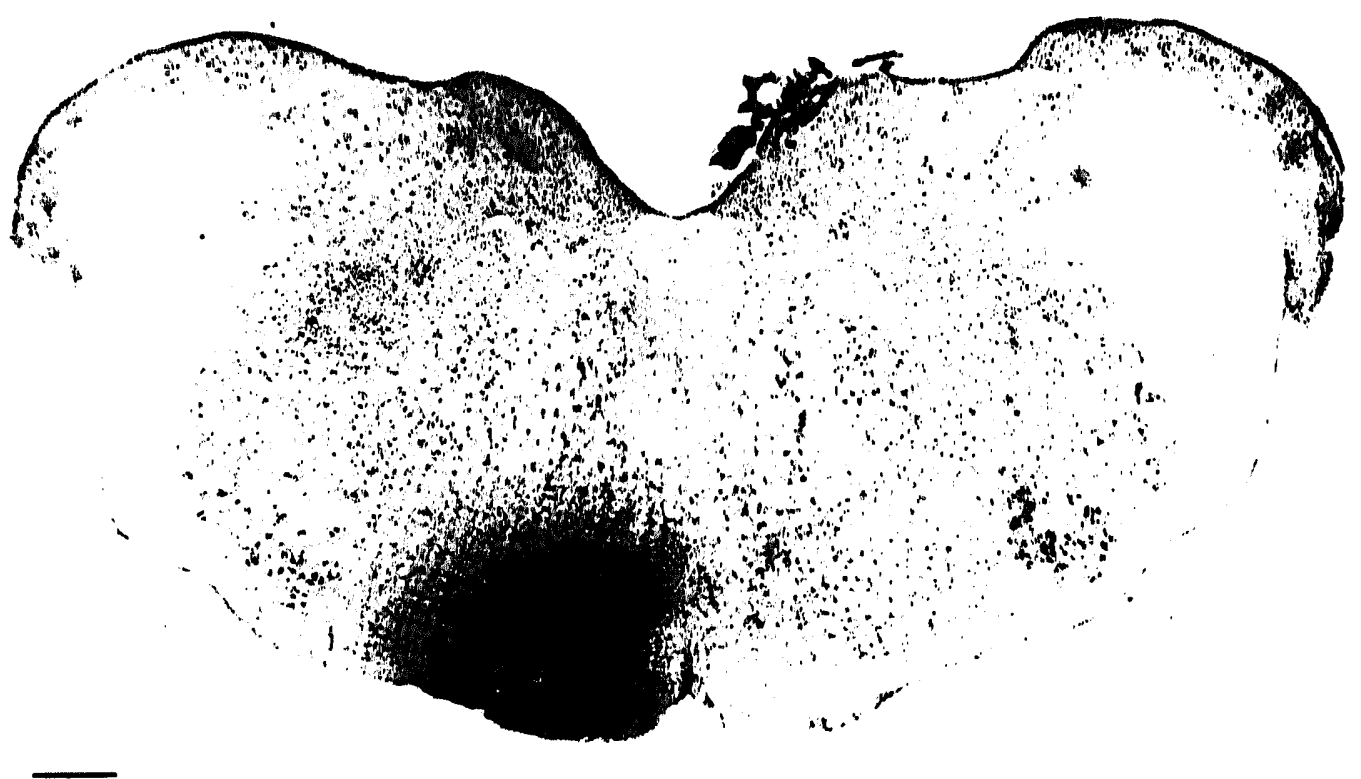

Fig. 1. Light micrograph of the wheat germ agglutinin-horseradish peroxidase (WGA-HRP) injection site in the ventromedial part of the rat lower brainstem at the level of the caudal facial nucleus. Bar $=0.5 \mathrm{~mm}$. 
site also included part of the rostral inferior olive and the nucleus raphe magnus.

Light microscopic examination of the semithin sections from the 5th and 6th lumbar segments showed anterograde WGA-HRP labeling bilaterally, with a clear ipsilateral predominance. Most labeling was seen in the motoneuronal cell groups in the ventral horn (c.f. refs. $10,11)$. Several retrogradely labeled cells were present, mostly in the contralateral intermediate zone, and only a few on the ipsilateral side, but not in the direct vicinity of the lateral motoneuronal cell groups. A more detailed description of the light microscopic findings has been given previously ${ }^{11}$. In the ultrathin sections several WGA-HRP labeled structures were present in addition to profiles which carried several gold particles, indicating the presence of glycine. A structure was considered to be labeled for glycine if the number of gold particles overlying the terminal was at least 8 times the number of gold particles overlying nearby unlabeled structures (terminals and dendrites). Although a detailed study of the glycinergic structures was not performed, it was noted that most of the glycinergic terminals were of the F-type and that (mostly myelinated) axonal profiles were often labeled with a larger number of gold particles than the terminal profiles. Axo-axonic (presynaptic) terminal arrangements involving glycinergic terminals were not encountered. The latter finding emphasizes the specificity of the glycine antibody, since presynaptic terminals in the motoneuronal cell groups are strongly immunoreactive for $G A B A^{12}$. In this study, attention was focused on WGA-HRP labeled terminals, therefore other WGAHRP labeled structures were discarded. A total of $\mathbf{4 4 8}$ WGA-HRP labeled terminal profiles were encountered. Three types of terminals were labeled with the WGAHRP reaction product: F-type terminals (70\%), S-type terminals (19\%) and G-type terminals (11\%). These results are in general agreement with the findings of previous studies ${ }^{10,11,13}$. For each WGA-HRP labeled terminal profile it was determined whether it was also labeled for glycine (double labeled). It was found that $15 \%$ of the WGA-HRP labeled terminals were double labeled for glycine (Fig. 2). When considering the different types of terminals it was found that $19 \%$ of the WGA-HRP labeled F-type terminals and 7\% of the S-type terminals were double labeled. G-type terminals were never double labeled. When considering only the double labeled terminal profiles, it was found that $91 \%$ were F-type (Figs. 3-5) and 9\% were S-type. The double labeled terminals established a synapse in $68 \%$ of the cases. These synapses were made with proximal dendrites (containing ribosomes) (44\%) and with distal dendrites (36\%) (Figs. 3 and 5) and to a lesser extent (20\%) with cell somata (Fig. 4C). Axo-axonic (pre-synaptic) contacts were never established by any of the labeled terminals.

The present experiment showed that in the lumbar motoneuronal cell groups approximately $15 \%$ of the terminals, which were labeled with WGA-HRP from the ventromedial reticular formation, contained glycine. In a similar experiment ${ }^{11}$ in which WGA-HRP anterograde tracing was combined with postembedding immunocytochemistry for GABA, it was found that $40 \%$ of the descending brainstem projections to lumbar motoneurons contained GABA. This percentage was considered as rather accurate since the same technique applied to other systems resulted in nearly $100 \%$ double labeling ${ }^{7}$, ${ }^{34}$. Whether such a high yield can also be obtained with the glycine antibody is not known. However, it seems likely that the properties of the glycine antibody are similar to those of the GABA antibody since (1) glycine and GABA are both small amino acid transmitters, (2) the glycine and GABA antibodies were raised in a similar manner (conjugated to glutaraldehyde) and in the same species (rabbit) and (3) both antibodies were used in a similar postembedding procedure. This would mean that the $15 \%$ double labeling should also be considered as a rather accurate figure. If the glycine antibody would be less sensitive as compared to the GABA antibody, the $15 \%$ of double labeling found in the present experiment should be regarded as an underestimate.

In a previous study ${ }^{13}$ we have shown that the majority of the terminals, autoradiographically labeled from the ventromedial reticular formation, contacted HRP-la-

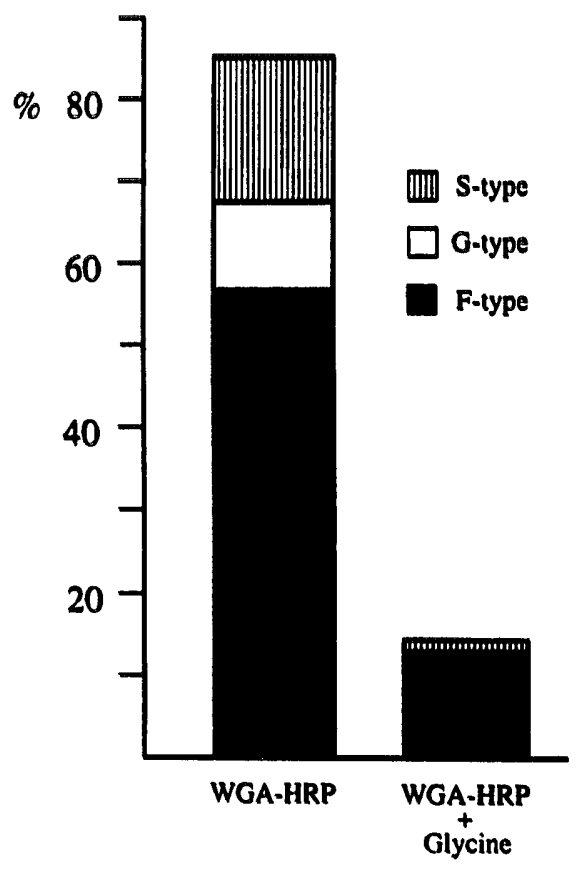

Fig. 2. Histogram showing the percentages of all terminals, labeled with WGA-HRP from the ventromedial lower brainstem, which were glycinergic (right column) or non-glycinergic (left column). The frequency of the F-, G- and S-types of terminals is indicated. 

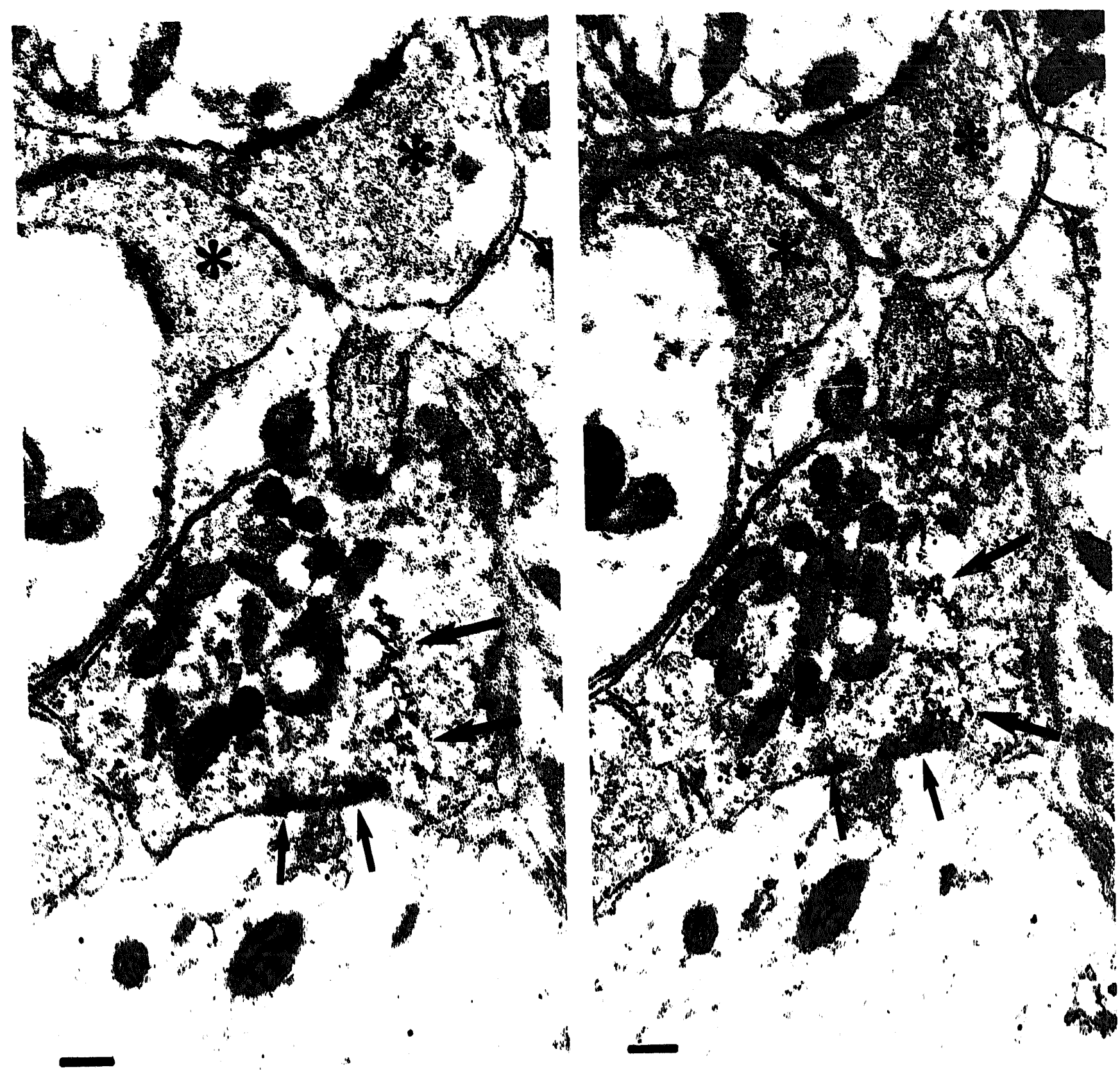

Fig. 3. Electronmicrographs of two adjacent sections from the rat $L_{s}$ lateral motoneuronal cell groups, showing F-type terminal profiles which were double labeled with a small amount of WGA-HRP reaction product (large arrows) and many gold particles, indicating that the terminals originated from the ventromedial reticular formation and contained glycine as a transnitter. Small arrows indicate a possible synaptic junction with part of a proximal dendrite. Asterisks indicate unlabeled terminal profiles. Bar $=0.5 \mu \mathrm{m}$.

beled motoneurons in the lumbar spinal cord. It is assumed, therefore, that also in the present study on the same system, the majority of the WGA-HRP labeled terminals, including the glycinergic ones, contacted motoneurons (for a more detailed discussion, see ref. 11). When the present finding on the glycinergic brainstem projections to lumbar motoneurons are combined with the previous finding ${ }^{11}$ that $40 \%$ of these projections contained GABA, it may be concluded that over $50 \%$ of the descending brainstem projections to spinal motoneurons contain either GABA or glycine. Since glycine and
GABA are the main inhibitory transmitters in the spinal cord (for review see ref. 16), it seems likely that over $50 \%$ of the projections descending from the ventromedial brainstem exert an inhibitory effect on spinal motoneurons. A further comparison of the data obtained in the two experiments show that $55 \%$ of the F-type terminals originating in the ventromedial reticular formation contained GABA, while the present data showed that $19 \%$ contained glycine. Thus $74 \%(55 \%+19 \%)$ of the F-type terminals contain either glycine or GABA, leaving approximately $26 \%$ still unaccounted for. Since F-type 

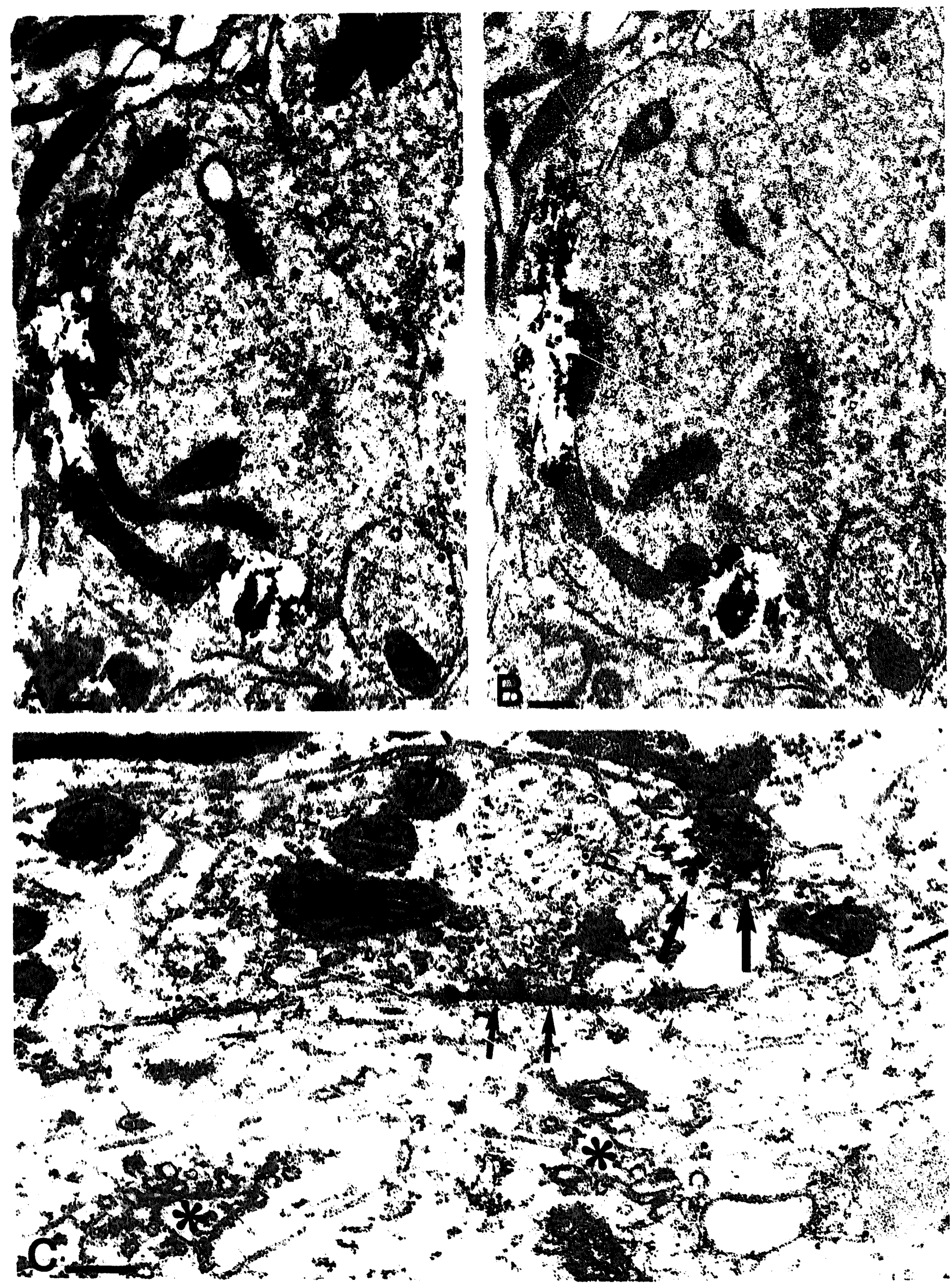
Fig. 4. Electronmicrographs from the rat $L_{5}(a, b)$ and $L_{6}$ (c) lateral motoneuronal cell groups. The terminal profiles were labeled with WGA-HRP reaction product from the ventro-medial reticular formation and contained glycine as indicated by the many gold particles overlying the terminals. Bar $=0.5 \mu \mathrm{m}$. a,b: two sections taken from a row of 5 serial sections. The WGA-HRP reaction product is clearly visible on the left and at the bottom of the terminal. An unlabeled terminal is situated very close to the double labeled terminal (top right). The electron dense material in the areas of contact (arrowheads in a) show the characteristics of puncta adhaerentia rather than synaptic junctions. c: a double labeled terminal of the F-type, establishing a symmetzical synapse with a cell soma, containing a Golgi apparatus (asterisks). Large arrows indicate the WGA-HRP reaction product.

$\leftarrow$

terminals are generally associated with an inhibitory transmitter ${ }^{30}$, it is difficult to suggest which transmitter, apart from GABA and glycine would be present in the remaining $26 \%$ of the F-type terminals. However, it should be kept in mind that it is increasingly difficult to reliably categorize a terminal, when the tissue has been extensively processed as in the present experiment. Moreover, the various data were obtained from separate studies and should not be treated as one experiment. Therefore final conclusions cannot be drawn at this point and additional experiments, combining GABA and glycine immunocytochemistry within the same experiment are needed to resolve these problems and to determine whether co-existence of GABA and glycine may occur in the descending brainstem projections.

An important indication of the functional significance of the descending brainstem projections was provided by Magoun and Rhines ${ }^{21}$ in 1946 . They were the first to show that electrical stimulation of the cat medial lower brainstem resulted in inhibition of spinal reflexes, a finding confirmed in later studies ${ }^{15,20}$. This electrophysiologically identified 'inhibitory center of Magoun' in the cat may well correspond to the area in the rat from which the GABA- and glycinergic spinal projections, which we have identified anatomically, are derived. In this respect it is interesting to note the differential effects obtained after electrical or chemical stimulation of neurons in different parts of the cat lower brainstem ${ }^{4}$. Stimulation of the ventromedial reticular formation resulted in inhibition of spinal reflexes, which is in agreement with forementioned studies. However, after stimulation of the adjacent raphe, spinal reflexes were mainly facilitated (c.f.

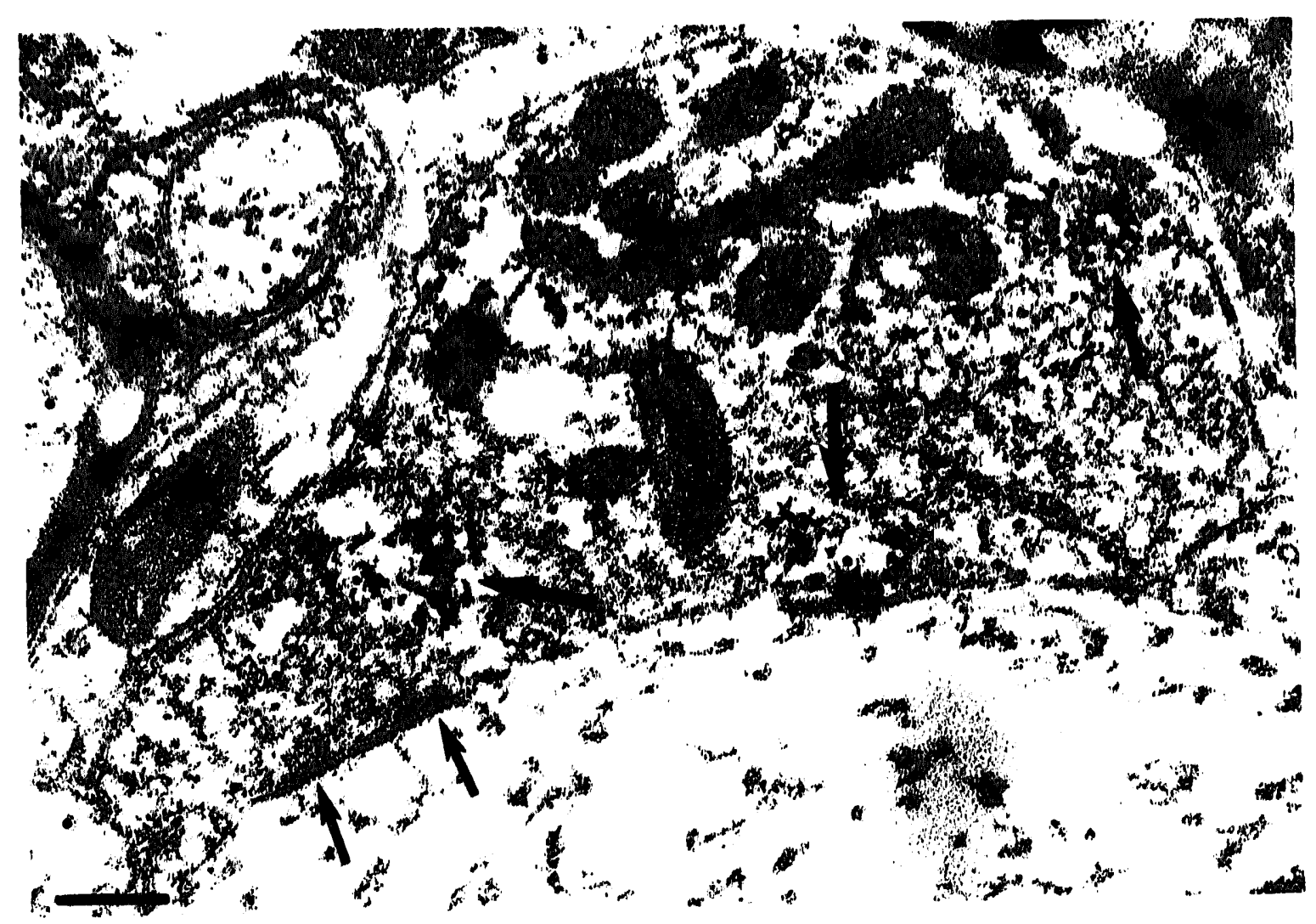

Fig. 5. Electronmicrograph from the rat $L_{5}$ lateral motoneuronal cell groups, showing an F-type terminal with WGA-HRP reaction product (large arrows) and inany gold particles. Small arrows indicate a symmetrical synaptic junction with a proximal dendrite, containing ribosomes (not visible on this part of the micrograph). Bar $=0.5 \mu \mathrm{m}$. 
refs. 3, 8, 27). This difference can be explained by our anatomical data: the majority of the terminals in the spinal motoneuronal cell groups, which are derived from the raphe nuclei, are of the G-type and contain seroto$\operatorname{nin}^{31}$ (for review see ref. 14), which has been shown to exert a facilitatory effect on spinal motoneurons ${ }^{35}$. In contrast the majority of the terminals on spinal motoneurons, which are derived from the adjacent ventro-medial reticular formation are of the F-type and contain the inhibitory transmitters GABA and glycine. Thus it seems likely that the descending facilitory and inhibitory projections from the lower brainstem to spinal motoneurons are, at least in part, mediated through direct monosynaptic connections with those motoneurons.

It is still unclear under which circumstances the projections from the ventromedial lower brainstem to spinal motoneurons are functionally active. In respect to the glycinergic fibers within these projections, it is tempting to assume that they are involved in producing muscle atonia during rapid eye movement (REM)sleep. The main reasons for this assumption are that (1) muscle atonia can be produced by chemically stimulating the area in the lower brainstem from which the descending glycinergic projections originate ${ }^{17}$ and (2) glycine was

1 Andrezik. J.A. and Beitz. A.J., Reticular formation, central grey and related tegmental nuclei. In G. Paxinos (Ed.). The Rat Nervous System, Vol 2, Hindbrain and Spinal Cord, Academic Press. Austrulia, 1985, pp. 1-28.

2 Bowker, R.M. and Abbott. L.C.. Quantitative re-evaluation of descending serotonergic and non-serotonergic projections from the medulla of the rodent: evidence for extensive co-existence of serotonin and peptides in the same spinally projecting neurons, but not from the nucleus raphe magnus, Brain Research, 512 (1990) $15=25$.

3 Cardona, A, and Rudomin, P., Activation of brainstem sero. tonergic pathways decreases homosynaptic depression of mono. synaptic responses of frog spinal motoneurons, Brain Research. 280 (1983) 373-378.

4 Chai, C.Y., Lin, Y.F., Wang, H.Y., Wu, W.C., Yen, C.T., Kuo, J.S. and Wayner, M.J., Inhibition of spinal reflexes by paramedian reticular nucleus, Brain Res. Bull., 25 (1990) 581-588.

5 Chase, M.H., Soja, P.J. and Morales, F.R., Evidence that glycine mediates the postsynaptic potentials that inhibit lumbar motoneurons during the atonia of active sleep. J. Neurosci., 9 (1989) 743-751.

6 Dahlström, A. and Fuxe, K., Evidence for the existence of monoamine-containing neurons in the central nervous system. II. Experimentally induced changes in the intraneuronal amine levels of bulbospinal neuron systems, Acra Physiol, Scand, 64 (1965) 6-36.

7 De Zecuw, C.I., Holstege, J.C.. Calkoen, F., Ruigrok, T.J.H. and Voogd. J., A new combination of WGA.HRP anterograde tracing and GABA-immunocytochemistry applied to afferents of the cat inferior olive at the ultrastructural level, Brain Research, 447 (1988) 369-375.

8 Fung. S.J. and Barnes. C.D. Raphé-produced excitation of spinal cord motoneurons in the cat. Neurosci. Lett., 103 (1989) 185-190.

9 Graham. R.C. and Karnovsky, M.J., The early stages of absorption of injected horseradish peroxidase in the proximal tu- shown ${ }^{29}$ to be the main transmitter responsible for the strong inhibition of lumbar motoneurons after electrical stimulation in the ventromedial lower brainstem during REM sleep (see also ref. 5). However, these studies also suggested that the connection between the lower brainstem and the motoneurons were not monosynaptic and involved one or more interneurons in the spinal cord, but so far these interneurons have not been identified. In contrast, it was found ${ }^{25}$ that one of the interneuronal candidates for this inhibition, the Renshaw cell, was itself inhibited during REM sleep. This indicated that not only motoneurons but also interncurons, involved in motor control, are inhibited during REM sleep. It may well be that the glycinergic projection from the lower brainstem is responsible for the simultaneous inhibition of both spinal motoneurons and interneurons during REM sleep.

The authors would like to thank Dr. J. Voogd for reading the manuscript, Mr. E. Dalm and Mr. H. van den Burg for their help with the surgery and Mrs. H. Goedknegt for her technical assistance. This investigation was supported by Grant $900-550-072$ from the Foundation for Medical Research MEDIGON, which is subsidized by the Netherlands Research Organization (NWO).

bules of the mouse kidney. Ultrastructural cytochemistry by a new terhnique, J. Histochem. Cytochem., 14 (1966) 291-302.

10 Holstege, J.C., Brainstem projections to lumbar motoneurons in rat. II. An ultrastructural study by means of the anterograde transport of wheat-germ agglutinin coupled to horseradish peroxidase and using the tetramethyl benzidine reaction. Neuro. science, 21 (1987) 369-376.

11 Holstege, J.C.. Ulirastructural evidence for GABAurgic brain stem projections to spinal motoneurons in the rat. $J$. Neurosci., 11 (1991) 159-167.

12 Holstege, J,C, and Calkoen, F., The distribution of GABA in lumbar motoneuronal cell groups. A quantitative ultrastructural study in rat, Brain Research, 530 (1990) 130-137.

13 Holstege, J.C. and Kuypers, H.G.J.M., Brainstem projections to lumbar motoneurons in rat. I. An ultrastructural study using autoradiography and the combination of autoradiography and HRP histochemistry, Neurascience, 21 (1987) 345-367.

14 Holstege, J.C. and Kuypers, H.G.J.M., Brainstem projections to spinal motoneurons: an update, Neuroscience, 23 (1987) 809821.

15 Jankowska, E., Lund, S., Lundberg, A. and Pompeiano, O., Inhibitory effects evoked through ventral reticulospinal pathways, Arch. Ital. Biol., 106 (1968) 124-140.

16 Krnjévic, K. Transmitters in motor systems. In J.M. Brookhart, V.B. Mountcastle, V.B. Brooks and S.R. Geiger (Eds.), Handbook of Physiology, the Nervous System Vol. II, Motor Control part I, American Physiol. Society, Bethesda, 1981, pp. 107-155.

17 Lai, Y.Y. and Siegel, J.M., Medullary regions mediating atonia, J. Neurosci., 8 (1988) 4790-4796.

18 Lemann, W., Saper, C.B., Rye, D.B. and Wainer, B.H., Stabilization of TMB reaction product for electron microscopic retrograde and anterograde fiber tracing, Brain Res. Bull., 14 (1985) 277-281.

i9 Ljungdahl, A. and Hökfelt, T., Autoradiographic uptake patterns of $\left[{ }^{3} \mathrm{H}\right] \mathrm{GABA}$ and $\left[{ }^{3} \mathrm{H}\right] \mathrm{glycine}$ in central nervous tissues with special reference to the cat spinal cord, Brain Research, 62 
(1973) 587-595.

20 Llinas, R. and Terzuolo, C.A., Mechanisms of supraspinal actions upon spinal cord activities. Reticular inhibitory mechanisms on alpha-extensor motoneurons, J. Neurophysiol., 27 (1964) 579-591.

21 Magoun, H.W. and Rhines, R., An inhibitory mechanism in the bulbar reticular formation, J. Neurophysiol., 9 (1946) 165-171.

22 Matus, A.I. and Dennison, M.E., Autoradiographic localisation of tritiated glycine at 'fiat-vesicle' synapses in spinal cord, Brain Research, 32 (1971) 195-19?.

23 McLaughlin, B.J., Barber, R., Saito, K., Roberts, E. and Wu, J.-Y., Immunocytochemical localization of glutamate decarboxylase in the rat spinal cord, J. Comp. Neurol., 164 (1975) 305322.

24 Mesulam, M.-M., Tetramethyl benzidine for horseradish peroxidase neurohistochemistry: a non-carcinogenic blue reactionproduct with superior sensitivity for visualizing neural afferents and efferents, $J$. Histochem. Cytochem., 26 (1978) 106-117.

25 Morales, F.R., Engelhardt, J.K., Pereda, E.P., Yamuy, J. and Chase, M.H., Renshaw cells are inactive during motor inhibition elicited by pontine microinjection of carbachol, Neurosci. Lett., 86 (1988) 289-295.

26 Muller, L.L. and Jacks, T.J., Rapid chemical dehydration of samples for electron microscopic examinations, J. Histochem. Cytochem., 23 (1975) 107-110.

27 Roberts, M.H., Davies, M., Girdlestone, D. and Foster, G.A., Effects of 5-hydroxytryptamine agonists and antagonists on the responses of rat spinal motoneurons to raphe obscurus stimulation, Br. J. Pharmacol., 95 (1988) 437-448.
28 Skagerberg, G. and Björklund, A., Topographic principles in the spinal projections of serotonergic and non-serotonergic brainstem neurons in the rat, Neuroscience, 15 (1985) 445-480.

29 Soja, P.J., Morales, F.R., Baranyi, A. and Chase, M.H., Effect of inhibitory amino acid antagonists on IPSPs induced in lumbar motoneurons upon stimulation of the nucleus reticularis gigantocellularis during active sleep, Brain Research, 423 (1987) 353-358.

30 Uchizono, K., Excitatory and inhibitory synapses in the cat spinal cord, Jpn. J. Physiol., 16 (1966) 570-575.

31 Ulfhake, B., Arvidsson, U., Cullheim, S., Hökfelt, T., Brodin, E., Verhofstad, A. and Visser, T., An ultrastructural study of 5-hydroxytryptamine-, thyrotropin-releasing hormone- and substance P-immunoreactive axonal boutons in the motor nucleus of spinal cord segments L7-S1 in the adult cat, Neuroscience, 23 (1987) 917-929.

32 Van den Pol, A.N. and Gorcs, T., Glycine and glycine receptor immunoreactivity in brain and spinal cord, J. Neurosci., 8 (1988) 472-492.

33 Wenthold, R.J., Huie, D., Altschuler, R.A. and Reeks, K.A., Glycine immunoreactivity localized in the cochlear nucleus and superior olivary complex, Neuroscience, 22 (1987) 897-912.

34 Wentzel, P.R., Holstege, J.C., Thunnissen, I.E. and Voogd, J., Ultrastructural evidence for GABA as inhibitory transmitter in the vestibulo-oculomotor projection in the rabbil, Eur. J. Neurosci., 2 (1989) 33.

35 White, S.R. and Neuman, R.S., Facilitation of spinal motoneurone excitability by 5 -hydroxytryptamine and noradrenaline, Brain Research, 188 (1980) 199-127. 